\title{
Research on the Construction of Curriculum Teaching Mode Integrating Workshop Management into Teaching
}

\author{
Xiaoping Yang \\ Lanzhou Vocational Technical College, Gansu 730050, Lanzhou, China.
}

\begin{abstract}
In recent years, with the deepening of the teaching reform of "integration of production and education" in colleges and universities in our country, the construction of a curriculum teaching model that integrates workshop management with teaching has gradually become an important direction of teaching reform in many vocational colleges. This article focuses on the "preparatory stage of the construction of a course teaching model integrating workshop management with teaching", "the process stage of the construction of a course teaching model integrating workshop management with teaching", and "assessment of the construction of a course teaching model integrating workshop management with teaching" "Stage" these aspects are discussed, hoping to further improve the construction of the curriculum teaching model that integrates workshop management with teaching, and comprehensively improve the quality of China's vocational education and teaching.
\end{abstract}

Keywords: Workshop Management; Teaching; Teaching Mode; Construction Research

Since the Ministry of Education issued the "Opinions on Trial Implementation of Work-Study Combination and Part-work-Study in Vocational Colleges", many vocational colleges in China have begun to vigorously promote the "integration of production and education", moving in the direction of "school-enterprise cooperation, integration of production and education" Education and teaching reform. In this context, the construction of a curriculum teaching model that integrates workshop management with teaching has become an important content of education and teaching reform in many vocational colleges. Practice has proved that the curriculum teaching model that integrates workshop management with teaching can better realize the "integration of theory and practice", which is conducive to improving the quality of vocational education and teaching in China. The construction of a curriculum teaching model that integrates workshop management with teaching can be divided into three stages: "preparation stage", "process stage" and "assessment stage".

\section{The "preparation stage" of the construction of a curriculum teaching model that integrates workshop management with teaching}

\subsection{Build a module course system centered on skill training}

In the "preparation phase" of the construction of a course teaching model integrating workshop management and teaching, a modular course system with "skill training" as the core must be established. First, the professional module. Taking mechanical design and manufacturing as an example, it can be divided into first-level module, second-level module, and third-level module. The first-level modules include basic fitter skills module, scraping and grinding module, measurement module, assembly module, etc. On the basis of the first-level module, the second-level modules include a chipping module, a scribing module, a sawing module, and a filing module. [1] On the basis of the secondlevel module, the third-level module includes filing cuboid, curved surface filing, and single plane filing. The content of module division gradually progresses and will become more and more specific; second, topic modules. After the

Copyright $\odot 2020$ Xiaoping Yang

doi: $10.18282 /$ le.v9i6.1306

This is an open-access article distributed under the terms of the Creative Commons Attribution Non-Commercial License

(http://creativecommons.org/licenses/by-nc/4.0/), which permits unrestricted non-commercial use, distribution, and reproduction in any medium, provided the original work is properly cited. 
division of professional modules, the third-level modules can be subdivided into several topics, and practical training and teaching can be carried out around topics such as topic goals, topic design, and technical requirements. In general, the third-level modules are arranged in the order from "basic" to "advanced". In this way, it can well reflect the connotative relationship between various topics; third, module courses. Choose a topic, use it as a unit of the course, and construct a topic module. When several topics are combined, a third-level module can be constructed. Then, referring to the framework of the three-level module, a module course with the "first-level module" as the core can be formed. Through the establishment of such a module course, a brand-new course system can finally be created.

\subsection{Construct training venues that can meet different levels of technicians}

After the establishment of a module course system centered on "skills training", the construction of training venues is also very important. In order to better cultivate students' practical skills, schools can build training venues according to the first and second modules. Specifically, different training rooms can be built, such as: fitter marking training room, scraping training room, fitter filing training room, precision grinding training room, hole and thread processing training room, etc. [2]. Such a training venue can meet the training needs of technicians of different levels. Regarding the number of training venues, planning should be combined with the actual situation of the school. The main factors considered are: the number of students, course content, school hours, etc. In order for every student to have the opportunity to exercise, the school must ensure that students have independent workstations in every training venue.

\subsection{Strengthen the training and learning of the integrated teacher team}

In addition to the curriculum system and training venues, in the "preparation phase" of the construction of a curriculum teaching model that integrates workshop management and teaching, there is another important task to build the teaching team. The construction of a curriculum teaching model that integrates workshop management with teaching puts forward higher requirements for teachers. Teachers must not only master a wealth of theoretical knowledge, but also have strong practical application capabilities. How to strengthen the construction of the teaching team? The first is to establish an "integrated teaching team" based on the teaching situation of "module courses + training venues". This teaching team should include theoretical backbone teachers and practical elite teachers. In daily teaching activities, theoretical teachers and practical teachers should communicate more, interact more, learn from each other's advantages, and achieve common progress [3]; second, the school can arrange for teachers to go to the front line of the company for research and make teachers understand The actual needs of enterprise development will improve the concept and methods of educating people, and promote the efficient matching of "employment of enterprises" and "employment of students".

\section{The "process stage" of the construction of a course teaching model integrating workshop management with teaching}

\subsection{About the functional layout of the training workshop}

In the "process stage" of the construction of a curriculum teaching model that integrates workshop management with teaching, schools should attach great importance to the functional layout of the training workshop. The "training workshop" is the main site for the implementation of the combination of production and education. When carrying out the functional layout, the school should combine the "production requirements" and "learning requirements" to create a multi-functional training workshop. For example, in the training workshop, soundproof glass can be used to divide a "learning area" [4] so that students can focus on discussion and study. For another example, in the learning area, some information-based monitoring equipment can be placed to record the operation of the workshop in real time, so that students can collect information and conduct dynamic analysis.

\subsection{Detailed selection and procurement process}

In addition to the importance of the functional layout of the workshop, the school should also consciously guide students in the selection and procurement, and the specific process of selection and procurement should be detailed. On the one hand, in the selection process, machine tools must meet multiple purposes, such as order production, employee training, education and teaching, competitions, etc. Generally speaking, for the choice of machine tool equipment, it is necessary to choose enterprise production equipment, not teaching equipment. Only enterprise production equipment has high performance and can meet actual production needs. In the process of constructing a course teaching model that 
integrates workshop management with teaching, some unexpected situations may occur, such as equipment failures, machine failures, etc., which not only affect teaching, but also affect production. Therefore, this link of model selection is very important; on the other hand, in the procurement link, the purchase of machine tool equipment is mainly applied in accordance with the process of "special construction funds" [5]. In reality, it can be purchased by the school or jointly purchased by the school and enterprise. The procurement process is generally: application by the teaching and research section, approval by school, and finally deducted from the enterprise processing fee.

\subsection{Pay attention to the maintenance and repair of machine tools}

In the course of constructing a course teaching model that integrates workshop management with teaching, attention should be paid to the maintenance and repair of machine tool equipment: first, set the maintenance and repair of machine tool equipment as daily basic work, and strictly implement it; second, , Regularly arrange special personnel to check the operation of machine tools and equipment, so as to prevent them; third, improve the efficiency of machine tool maintenance, and integrate the maintenance and repair of machine tools into the teaching of combining production and education; fourth, improve the maintenance and repair of machine tools In the maintenance process, each maintenance and repair information is archived. When minor faults occur, teachers will lead students to solve them together, and when major faults occur, they will be handed over to a special organization for processing [6].

\section{The "assessment phase" of the construction of a curriculum teaching model that integrates workshop management with teaching}

Practice has proved that the curriculum teaching model that integrates workshop management with teaching can better realize the "integration of theory and practice", which is conducive to improving the quality of vocational education and teaching in China. In the "assessment stage" of the construction of a curriculum teaching model that integrates workshop management with teaching, the traditional assessment system has gradually been unable to adapt to the new teaching model. Universities can build a "three-level evaluation system" around the "module curriculum system": In the third level of evaluation, as long as students complete the module topic, an evaluation will be conducted;

In the second-level evaluation, when students complete the second-level module or the third-level module, a comprehensive evaluation is organized. In this process, if the student does not pass the comprehensive evaluation, they need to study again until they pass the assessment;

In the first-level evaluation, the results of the third-level evaluation and the second-level evaluation should be integrated to determine the final score.

\section{Conclusion}

The construction of a curriculum teaching model that integrates workshop management with teaching is a teaching innovation of "theory and practice integration" and an important measure to implement the "integration of production and education" in vocational education. Under such a teaching mode, students can better apply theoretical knowledge to practice, and test and consolidate theoretical knowledge through practice, which is conducive to improving students' comprehensive ability. The ultimate goal of any kind of teaching model innovation is to better improve the comprehensive ability of students. The curriculum teaching model that integrates workshop management and teaching has returned to the "applied" nature of vocational education, which is meaningful.

\section{References}

1. Liu Meng, Zheng Xuan. OBE mode combined with PBL teaching method to realize the transformation of local colleges and universities education paradigm [J]. Journal of Qilu Normal University, 2019, 34(3): 31-35, 61.

2. Yang Xi, Yao Lan. Some thoughts on optimizing the production environment of GMP pharmaceutical workshops, 2017, 21(17): 153.

3. Li Binglong, Hao Liyong, Liu Changli, et al. Exploration and practice of smooth and efficient operation of the comprehensive experimental teaching center of pharmacy[J]. Experimental Technology and Management, 2017, 1(34): 214-216 